\title{
Screening to detect asymptomatic shedding of herpes simplex virus (HSV) in women with recurrent genital HSV infection
}

\author{
S E BARTON,* L K WRIGHT, $\uparrow$ C M LINK,* AND P E MUNDAY*†
}

From the *Praed Street Clinic, St Mary's Hospital, London, and the †Division of Sexually Transmitted Diseases, MRC Clinical Research Centre, Harrow, Middlesex

SUMMARY To investigate the asymptomatic shedding of herpes simplex virus (HSV) from women with recurrent genital herpes infection, and to assess whether inapparent shedding could occur, eight such women were examined thrice weekly for one month. At each visit colposcopy was performed and multiple sites sampled for HSV. During the study four women had no recurrence of HSV infection, but four had at least one positive viral culture. One of these patients was asymptomatically shedding HSV on nine of her 11 clinic visits. Two episodes of urethral shedding were detected. In this group of patients the presence of inguinal lymphadenopathy was appreciably associated with the isolation of HSV from the urogenital tract.

\section{Introduction}

Genital herpes simplex virus (HSV) infection is the commonest cause of genital ulceration in women in the United Kingdom. One of the most difficult questions asked by patients with genital HSV infection is whether they can be infectious in the absence of symptoms. Most clinicians answer that this phenomenon, so called "asymptomatic shedding", has been observed but is believed to be rare and that there are no data to predict when it might occur. The term "asymptomatic shedding" is open to misinterpretation. It may be used to indicate isolation of HSV from a clinically obvious lesion of which the patient is unaware: or from a lesion, such as a cervical lesion, that is accessible to the doctor but not the patient; or from an intact, apparently normal, epithelial surface - that is, inapparent shedding.

There have been several studies of asymptomatic shedding in pregnant women, ${ }^{1-3}$ but other groups of women have been less intensively investigated. Guinan et al obtained cervical swabs once weekly from women with proved genital HSV infection and recorded asymptomatic shedding in one $(1.6 \%)$ of 64 patients. ${ }^{4}$ Adam et al followed up women with HSV infection who were taking part in a treatment trial, and claimed that five $(10 \%)$ out of 50 women were

Address for reprints: Dr P E Munday, Praed Street Clinic, St Mary's Hospital, Praed Street, London W2 INY

Accepted for publication 27 September 1985 shedding the virus. ${ }^{5}$ Though this was claimed to represent true asymptomatic shedding, specimens were obtained at visits initiated by patients, which suggested that some patients might have had symptoms that they did not attribute to HSV infection. Furthermore, the effect on viral shedding of the treatment under study, photoactivated proflavin treatment, is not known.

Two other groups of workers have studied women attending outpatient clinics. Ferrer et al took cervical and vaginal specimens for HSV culture from 123 women in a Puerto Rican sexually transmitted diseases (STD) clinic and described three $(2.5 \%)$ as asymptomatic vaginal shedders; however, one woman presented with symptoms of vaginitis and another with secondary syphilis. ${ }^{6}$ Similarly McCaughtry et al investigated 585 women attending a college health clinic and found five "asymptomatic" cervical shedders; four had clinical candidiasis and one vaginal bleeding. ${ }^{7}$ Thus serious doubts must be raised about whether these workers had detected true asymptomatic shedding or HSV infection in women with symptoms that they did not attribute to herpetic infection. Furthermore, the examination findings are not sufficiently detailed to decide whether these episodes were inapparent as well as supposedly asymptomatic. In an important study, Rattray et al selected six women with proved genital HSV infection and examined them twice weekly. ${ }^{8}$ Two women had episodes of asymptomatic viral shedding; one of them had shedding from the cervix on a single occasion, and 
the other on two occasions had shedding from the vulva, which was accompanied once by ulceration seen on examination.

To investigate asymptomatic shedding of HSV, we studied prospectively, both virologically and clinically, using the colposcope ${ }^{9}$ a group of women with recurrent genital HSV infection. We also examined the inguinal lymph nodes to investigate further the finding of Corey et al that about one third of recurrent episodes of HSV infection in women are accompanied by tender inguinal lymphadenopathy. ${ }^{10}$

\section{Patients and methods}

The same clinician examined thrice weekly for one month eight women with a history of culture proved genital HSV type 2 infection. Table I shows the demographic and clinical features of the eight patients. Women were selected because they were well motivated and able to attend often for the examinations and because they had expressed worries about asymptomatic shedding. During the study period each woman kept a diary to record symptoms, sexual activity, and stress events. At each visit this diary was discussed with the patient and she was asked the specific questions "Do you have any symptoms of a herpes attack?" and then "Do you have any symptoms at all?" The patient was then examined with particular attention being paid to palpation of inguinal lymph nodes, and a scoring system ranging from 0 to 3 was used to grade the degree of inguinal lymphadenopathy. The vulva, vagina, and cervix were examined with the naked eye and colposcope. Routine tests to exclude syphilis, gonorrhoea, and candidal and trichomonal infection were performed according to standard clinic procedures. Specimens for HSV culture were taken from the urethra, vulva (sweep of the labia majora), cervix, and any lesions seen with the naked eye or colposcope. Except for the culture for Neisseria gonorrhoeae and the serological test for syphilis, all tests mentioned were performed at every visit.

\section{HERPES SIMPLEX VIRUS ISOLATION}

Swabs were placed in $1 \mathrm{ml}$ of viral transport medium containing nutrient broth, penicillin $(1000 \mathrm{IU} / \mathrm{ml})$, streptomycin $(1000 \mathrm{IU} / \mathrm{ml})$, and ampicillin (50 $\mathrm{mg} / \mathrm{ml}$ ), and were processed immediately or stored at $-70^{\circ} \mathrm{C}$. A $0.2 \mathrm{ml}$ volume of the sample was inoculated into two tubes containing monolayers of human embryonic lung fibroblasts (MRC5, Flow Laboratories, Rickmansworth, England), which were incubated at $37^{\circ} \mathrm{C}$. The monolayers were observed daily for cytopathic effect. A specimen was considered to be negative if a characteristic change had not occurred after seven days. Monolayers exhibiting a cytopathic effect were harvested by scraping the cells into the medium, and the suspensions were frozen at $-70^{\circ} \mathrm{C}$ until used for virus typing.

\section{Results}

Though none of the patients believed that they had ever infected a sexual partner, all of them had reduced the incidence of sexual intercourse since HSV infection had been diagnosed. On detailed questioning this was found to be due to a fear of infecting their uninfected sexual partner, though the extent to which guilt feelings and other psychological manifestations of HSV infection also caused this was uncertain. The motivation of these women to be studied in such an intensive way, however, was directly related to their worries about asymptomatic shedding.

During the study period of 234 days and 88 patient visits, four of the women had no clinical or virological evidence of recurrences of HSV infection. The other four, however, each yielded at least one positive HSV culture, all of which were confirmed as HSV type 2.

TABLE I Characteristics of patients in study group

\begin{tabular}{|c|c|c|c|c|c|c|c|c|}
\hline $\begin{array}{l}\text { Demographicl } \\
\text { clinical features }\end{array}$ & Case 1 & Case 2 & Case 3 & Case 4 & Case 5 & Case 6 & Case 7 & Case 8 \\
\hline $\begin{array}{l}\text { Age (years) } \\
\text { Race } \\
\text { Marital status } \\
\text { Occupation } \\
\text { Parity } \\
\text { Contraception } \\
\text { Previous genital infection }\end{array}$ & \begin{tabular}{l}
23 \\
White \\
Single \\
Psychologist \\
$0+0$ \\
Cap \\
Candidal \\
\multicolumn{1}{c}{ vaginitis }
\end{tabular} & $\begin{array}{l}23 \\
\text { White } \\
\text { Single } \\
\text { Nurse } \\
0+0 \\
\text { Sheath } \\
\text { NGU } \\
\quad \text { contact }\end{array}$ & $\begin{array}{l}25 \\
\text { Black } \\
\text { Single } \\
\text { Secretary } \\
0+1 \\
\text { None } \\
\text { PID }\end{array}$ & $\begin{array}{l}33 \\
\text { White } \\
\text { Single } \\
\text { Designer } \\
1+2 \\
\text { Sheath } \\
\text { None }\end{array}$ & $\begin{array}{l}30 \\
\text { White } \\
\text { Single } \\
\text { Press Officer } \\
0+0 \\
\text { Oral } \\
\text { NGU } \\
\quad \text { contact }\end{array}$ & $\begin{array}{l}23 \\
\text { White } \\
\text { Single } \\
\text { Nurse } \\
0+0 \\
\text { Cap } \\
\text { Gonorrhoea }\end{array}$ & $\begin{array}{l}33 \\
\text { White } \\
\text { Single } \\
\text { Negotiator } \\
3+1 \\
\text { Sterilised } \\
\text { None }\end{array}$ & $\begin{array}{l}20 \\
\text { White } \\
\text { Single } \\
\text { Nurse } \\
0+1 \\
\text { Oral } \\
\text { None }\end{array}$ \\
\hline $\begin{array}{l}\text { Age at coitarche } \\
\text { Total lifetime partners } \\
\text { New partners }\end{array}$ & $\begin{array}{r}18 \\
5\end{array}$ & $\begin{array}{l}16 \\
20\end{array}$ & $\begin{array}{r}21 \\
3\end{array}$ & $\begin{array}{l}16 \\
30\end{array}$ & $\begin{array}{l}17 \\
15\end{array}$ & $\begin{array}{l}17 \\
10\end{array}$ & $\begin{array}{l}17 \\
10\end{array}$ & $\begin{array}{r}17 \\
1\end{array}$ \\
\hline $\begin{array}{l}\text { since diagnosis } \\
\text { Months since diagnosis } \\
\text { No of symptomatic }\end{array}$ & $\begin{array}{l}\mathbf{0} \\
\mathbf{3}\end{array}$ & $\begin{array}{l}2 \\
8\end{array}$ & $\begin{array}{l}0 \\
5\end{array}$ & $\begin{array}{l}0 \\
2\end{array}$ & $\begin{array}{l}1 \\
5\end{array}$ & $\begin{array}{l}1 \\
5\end{array}$ & $\begin{array}{l}2 \\
2\end{array}$ & $\begin{array}{l}0 \\
5\end{array}$ \\
\hline recurrences & 1 & 1 & 1 & 1 & 1 & 2 & 1 & 1 \\
\hline
\end{tabular}

NGU = non-gonococcal urethritis.

PID = pelvic infammatory disease 
The details of these patients are presented below.

CASE 3

One patient (case 3 ) had two reccurrences. On day 8 , despite her being asymptomatic, colposcopic examination of her right labium major showed erythema and vesicles from which HSV was isolated. The following day symptoms developed, and ulceration was visible to the naked eye. Viral culture was again positive on day 10 . On day 13 , though HSV was not isolated from the routine cervical sweep, a colposcopically directed swab of an ulcerated area (figure) gave positive results. The virus was not isolated from the vulva or cervix on day 15 , by which time the vulval lesion was a scab and the cervical ulcer had healed. On day 19 of the study the patient was asymptomatic, but a urethral swab was positive for HSV.

Thus, this patient had one vulval and cervical recurrence, which was initially asymptomatic but became symptomatic, and one asymptomatic inapparent urethral recurrence.

\section{CASE 5}

One patient (case 5) had two recurrences. On day 12 vulval erythema was seen colposcopically; by day 14 the patient had become symptomatic, the lesion being visible to the naked eye and culture positive. The virus was not isolated after day 17 from the typical ulcers, which had healed by day 20 . On day 27 a tiny vulval sore, which was culture positive, was seen colposcopically. At this visit the patient had no genital symptoms, but felt that she had experienced the prodromal symptoms of an attack for the previous two days. These symptoms, intermittent headache and backache, had disappeared on the day of the examination. She reported that these warnings were usually, but not inevitably, followed by vulval sores. By the next visit on day 29, the sores had crusted and the virus was not isolated. Thus this patient had one symptomatic vulval recurrence and one apparently asymptomatic vulval recurrence during the study period.

\section{CASE 6}

One patient (case 6) had one recurrence at three sites consecutively. On day 13 a virus positive colposcopically apparent cervical lesion was seen, but the patient was asymptomatic. Two days later a virus negative vaginal ulcer was seen and a symptomatic vulval recurrence, which was virus positive, began. By day 18 the cervical, vaginal, and vulval sites had healed and the virus was not isolated from them, but on the right buttock a virus positive vesicular eruption appeared, which caused considerable pain and healed after seven days.

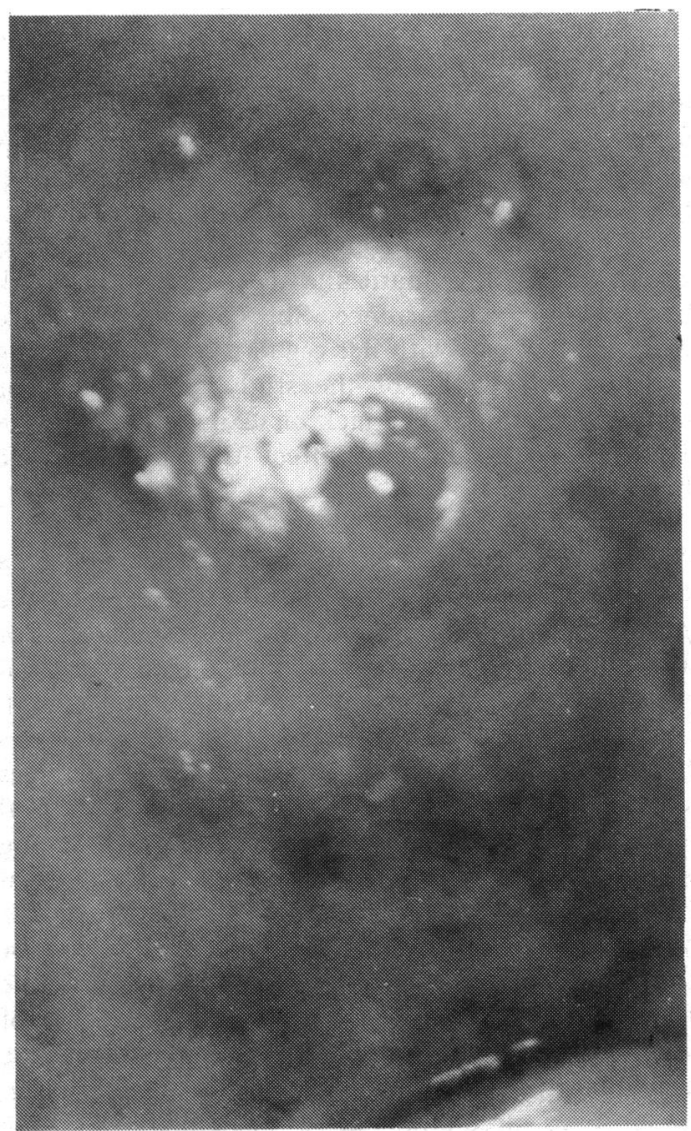

FIGURE Colpophotograph showing an ulcer and four vesicles on anterior lip of cervix of case 3.

Thus this patient had an initially asymptomatic cervical recurrence, followed by symptomatic vulval and buttock recurrences.

\section{CASE 8}

HSV was isolated from the urogenital tract of this patient at nine of 11 examinations (table II). She experienced symptoms of early morning dysuria on

TABLE II Clinical and virological findings of herpes simplex virus (HSV) in case 8

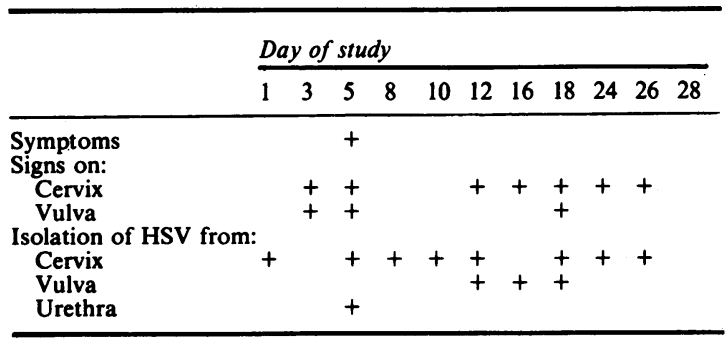

$+=$ positive findings. 
days 5 and 6, and on day $6 \mathrm{HSV}$ was isolated from the urethra. On day 18 she reported a white vaginal discharge, which had increased in amount over the previous two days. On colposcopic examination virus positive cervical and vulval lesions were seen, though they were not visible to the naked eye.

At all other times throughout the study period the patient was asymptomatic and at no time did she think that she had a recurrence. She continued to have sexual intercourse with her regular boyfriend during the first two weeks of the study, and then their relationship ended. The lack of sexual contact in the last two weeks did not affect the asymptomatic shedding of HSV.

ASSOCIATION OF HSV SHEDDING WITH OTHER FACTORS No appreciable association was found between the episodes of symptomatic or asymptomatic shedding of HSV and the pattern of sexual intercourse, menstrual cycle, stress events, or type of contraception used. Furthermore, there was no association between virus shedding and vaginal $\mathrm{pH}$ or the presence of leucocytes detected by the examination of Gram stained urethral or cervical smears. There was, however, a strong association between the presence of inguinal lymphadenopathy and virus shedding. A score of 2 or more, which indicated the presence of bilateral or tender unilateral inguinal lymphadenopathy (table III) had a sensitivity of $85.7 \%$ and a specificity of 92.4\% for predicting whether specimens from the urogenital tract would be virus positive. Furthermore, the positive predictive value was $78.3 \%$ and the negative predictive value was $95.4 \%$. This association was valid for all anatomical sites sampled. All patients had negative serological tests for syphilis, negative cultures for $N$ gonorrhoeae, and normal cervical cytology within three months after the study.

\section{Discussion}

The data on which to base the counselling of women with HSV infection about the problem of asymptomatic shedding are inadequate. We set out to obtain information about the patients in our study group to make individual counselling possible.

TABLE III Association between inguinal lymphadenopathy and isolation of herpes simplex virus (HSV) from the urogenital tract

\begin{tabular}{lcc}
\hline & \multicolumn{2}{c}{ No of patients whose culture result was: } \\
\cline { 2 - 3 } $\begin{array}{l}\text { Lymphadenopathy } \\
\text { score* }\end{array}$ & Positive & Negative \\
\hline$<2$ & 3 & 62 \\
$\geqslant 2$ & 18 & 5 \\
\hline $0=$ no lymphadenopathy; $1=$ & unilateral non-tender \\
lymphadenopathy, $2=$ bilateral non-tender lymphadenopathy or \\
tender unilateral \\
lymphadenopathy.
\end{tabular}

Sampling multiple anatomical sites and using the colposcope appears to have uncovered the "tip of an iceberg" of asymptomatic shedding of HSV in women. On at least one day when they did not have symptoms of HSV infection, four of our eight patients had HSV isolated from urogenital tract specimens. Thus they were a potential source of infection for their sexual partners, though the degree of risk is uncertain. Mertz et al found that $33 \%$ of source contacts were asymptomatic at the time they infected their sexual partners, ${ }^{11}$ so it seems likely that asymptomatic shedding constitutes an important health problem. There is no evidence to support the assertion that the relative risk of infection from an asymptomatic source contact may be less than from a symptomatic source and may be dependent on the recipients' immune status. ${ }^{12}$ Furthermore, the effect of the site of shedding on transmissibility is unknown.

The value of the colposcope, both to detect microscopic genital lesions and to direct swabs to lesions, is well shown in this study. In addition to the typical appearance of HSV infection of the cervix that has been described previously, ${ }^{13}$ we noted that ulceration was often preceded by increased local vascularity and vesicle formation. The use of colpophotography to record these lesions complemented the study records and helped to inform and educate the women.

The importance of our findings for trials of antiviral and other drugs intended to reduce the frequency of HSV recurrences is important, as such drugs might modify the disease and render symptomatic recurrences asymptomatic or inapparent. It seems prudent for all future study designs to include regular frequent (at least twice weekly) colposcopic examination, in conjunction with viral sampling from multiple sites, to exclude the possibility of asymptomatic shedding during and after the treatment period.

The value of the study in providing data for counselling these patients is that certain symptoms and signs emerged as being associated with virus positive episodes in these patients. Thus we could tell individual patients that mild dysuria, vaginal discharge, and inguinal lymphadenopathy were associated with their recurrences, though the patients had not observed any ulceration. They were therefore advised not to have sexual intercourse while these symptoms were present. This was important advice because several of our patients believed that a sore was the only symptom of HSV infection. This advice will be necessary until an easily performed reliable test to detect the presence of HSV within hours, rather than days, becomes available. We are currently evaluating the use of a rapid direct monoclonal antibody test to detect asymptomatic shedding of HSV in patients with recurrent genital HSV infection. 
Whether or not all anxious patients who worry about asymptomatic shedding can have a programme of frequent regular examinations and virological investigation depends on the resources of the individual clinic and the motivation of the patient. Though this may be time consuming, the reassurance to the patients who completed the study without any recurrence was valuable (even if of uncertain significance), and all patients benefited from knowing how their symptoms related to episodes of viral shedding. Indeed, to counsel patients with HSV infection properly, larger studies of this type must be performed. Only in this way will a method for predicting which patients become asymptomatic shedders, deciding what factors influence shedding, and assessing the effects of any proposed treatment be developed. We do not know if one episode of asymptomatic shedding means that others will necessarily occur, or if their incidence relates to the incidence of symptomatic recurrences.

Non-lesional prodromes have been described by Sacks in a study that relied totally on patient observations of whether a prodrome was followed by genital ulceration. ${ }^{14}$ One patient (case 5) in our study had a prodrome that was followed by an episode of asymptomatic vulval shedding of HSV from a microscopic vulval ulcer that could be seen only with the colposcope. It is thus essential for any investigators intending to comment on the incidence of non-lesional prodromes to make regular examinations, and if possible use colposcopy, to ascertain whether lesions really do occur.

One patient (case 8) was apparently infectious on nine of her 11 clinic visits, the virus being cultured from a variety of urogenital sites. Our options for management were either barrier contraception, prophylactic acyclovir, or counselling and careful follow up. The patient opted for continued follow up, as she had ended the relationship with her regular boyfriend and had no current sexual partner. She stopped shedding virus two weeks after the study period. Subsequent viral cultures at visits twice weekly for two months have not yielded a positive culture. We intend to continue to see her as often as she agrees and to manage her according to her needs.

The effect of this patient's frequent asymptomatic shedding on her risk of developing cervical intraepithelial neoplasia is not known. Though HSV infection of the cervix has been shown to increase the susceptibility of cervical cells to undergo atypical transformation, ${ }^{15}$ additional stimuli are needed to promote carcinogenesis. As sperm may act as such a stimulus, ${ }^{16}$ it is evident that women who have asymptomatic recurrent cervical HSV infection are at most risk because they will be having intercourse while the cervix is infected. Thus barrier contraception, as well as reducing the risk of transmission of HSV, might also reduce the woman's risk of developing cervical neoplasia.

References

1. Nahmias AJ, Josey WE, Naib ZM, Freeman MG, Fernandez RJ, Wheeler JH. Perinatal risk associated with maternal genital herpes simplex virus infection. Am J Obstet Gynecol 1971;110;825-36.

2- Bolognese RJ, Corson SC, Fuccillo DA, Traub R, Moder R, Sever JL. Herpesvirus hominis type II infection in asymptomatic pregnant women. Obstet Gynecol 1976;48:50710.

3. Vontver LA, Hickok DE, Brown Z, Reid L, Corey L. Recurrent genital herpes simplex virus infection in pregnancy: infant outcome and frequency of asymptomatic recurrences. $\mathrm{Am} \mathrm{J}$ Obstet Gynecol 1982;143:75-84.

4. Guinan ME, MacCalman J, Kern ER, Overall JC, Spruance SL. The course of untreated recurrent genital herpes simplex infection in 27 women. N Engl J Med 1981;304:759-63.

5. Adam E, Kaufman RH, Kirkovic RR, Meinick JL. Persistence of virus shedding in asymptomatic women after recovery from herpes genitalis. Obstet Gynecol 1979;54:171-3.

6. Ferrer RM, Kraiselburd EN, Kouri YH. Inapparent genital herpes simplex infection in women attending a venereal disease clinic. Sex Transm Dis 1984;11:91-3.

7. McCaughtry ML, Fleagle GS, Docherty JJ. Inapparent genital herpes simplex virus infection in college women. J Med Virol 1982;10:283-90.

8. Rattray MC, Corey L, Reeves WC, Vontver LA, Holmes KK. Recurrent genital herpes among women: symptomatic $v$. asymptomatic viral shedding. British Journal of Venereal Diseases 1978;54:262-5.

9. Barton SE, Munday PE, Davis JM, Tyms AS. Restriction enzyme analysis and herpes simplex infections. Lancet 1985;i:1448-9.

10. Corey L, Adams HG, Brown ZA, Holmes KK. Genital herpes simplex virus infections: clinical manifestations, course and complications. Ann Intern Med 1983;98:958-972.

11. Mertz GJ, Schmidt $O$, Jourden JL, et al. Frequency of acquisition of first-episode genital infection with herpes simplex virus from symptomatic and asymptomatic source contacts. Sex Transm Dis 1985;12:33-9.

12. Jaratt M. Herpes simplex infection. Arch Dermatol 1983;119:99103.

13. Coppleson M, Pixley E, Reid B. Colposcopy: a scientific and practical approach to the cervix and vagina in thealth and disease. Illinois: Thomas, 1978.

14. Sacks SL. Frequency and duration of patient-observed recurrent genital herpes simplex virus infection: characterisation of the nonlesional prodrome. $J$ Infect Dis 1984;150:873-7.

15. Fish EN, Tobin SM, Cooter NBE, Papsin FR. Update on the relation of Herpesvirus hominis type 2 to carcinoma of the cervix. Obstet Gynecol 1982;59:220-4.

16. Coppleson $\mathbf{M}$. The origin and nature of premalignant lesions of the cervix uteri. Int J Gynaecol Obstet 1970;8:539-41. 